\title{
Article \\ Effectiveness of Esterification Catalysts in the Synthesis of Poly(Ethylene Vanillate)
}

\author{
Eleftheria Xanthopoulou ${ }^{1,2}{ }^{-}$, Alexandra Zamboulis ${ }^{2}{ }^{-}$, Zoi Terzopoulou ${ }^{1,2}{ }^{-}$, Margaritis Kostoglou ${ }^{3}$, \\ Dimitrios N. Bikiaris ${ }^{2, *(D)}$ and George Z. Papageorgiou 1,4,*(D) \\ 1 Department of Chemistry, University of Ioannina, P.O. Box 1186, 45110 Ioannina, Greece; \\ elefthxanthopoulou@gmail.com (E.X.); terzoe@gmail.com (Z.T.) \\ 2 Laboratory of Polymer Chemistry and Technology, Department of Chemistry, Aristotle University of \\ Thessaloniki, 54124 Thessaloniki, Greece; azampouli@chem.auth.gr \\ 3 Laboratory of Chemical and Environmental Technology, Aristotle University of Thessaloniki, \\ 54124 Thessaloniki, Greece; kostoglu@chem.auth.gr \\ 4 Institute of Materials Science and Computing, University Research Center of Ioannina (URCI), \\ 45110 Ioannina, Greece \\ * Correspondence: dbic@chem.auth.gr (D.N.B.); gzpap@uoi.gr (G.Z.P.)
}

Citation: Xanthopoulou, E.;

Zamboulis, A.; Terzopoulou, Z.;

Kostoglou, M.; Bikiaris, D.N.;

Papageorgiou, G.Z. Effectiveness of Esterification Catalysts in the Synthesis of Poly(Ethylene Vanillate). Catalysts 2021, 11, 822. https:// doi.org/10.3390/catal11070822

Academic Editor: Eric M. Gaigneaux

Received: 8 June 2021

Accepted: 3 July 2021

Published: 6 July 2021

Publisher's Note: MDPI stays neutral with regard to jurisdictional claims in published maps and institutional affiliations.

Copyright: (C) 2021 by the authors Licensee MDPI, Basel, Switzerland. This article is an open access article distributed under the terms and conditions of the Creative Commons Attribution (CC BY) license (https:// creativecommons.org/licenses/by/ $4.0 /)$.
Abstract: Over the last few decades, bio-based polymers have attracted considerable attention from both academic and industrial fields regarding the minimization of the environmental impact arising from the excessive use of petrochemically-based polymeric materials. In this context, poly(ethylene vanillate) (PEV), an alipharomatic polyester prepared from 4-(2-hydroxyethoxy)-3-methoxybenzoic acid, a monomer originating from lignin-derived vanillic acid, has shown promising thermal and mechanical properties. Herein, the effects of three different catalysts, namely titanium butoxide (TBT), titanium isopropoxide (TIS), and antimony trioxide $\left(\mathrm{Sb}_{2} \mathrm{O}_{3}\right)$, on the synthesis of PEV via a two-stage melt polycondensation method are investigated. The progress of the reaction is assessed using various complementary techniques, such as intrinsic viscosity measurement (IV), end group analysis (AV), nuclear magnetic resonance spectroscopy (NMR), Fourier-transformed infrared spectroscopy (FTIR), and differential scanning calorimetry (DSC). The thermal stability of the produced polyesters is studied by evolved gas analysis mass spectrometry (EGA-MS). Moreover, as the discoloration in polymers affects their applications, color measurement is performed here. Finally, theoretical kinetic studies are carried out to rationalize the experimental observations.

Keywords: poly(ethylene vanillate); synthesis; bio-based polyesters; vanillic acid; catalysts; thermal properties

\section{Introduction}

Contemporary industrial polymerization technologies make the production of versatile polymeric materials with highly tunable properties possible and subsequently a plethora of applications in areas including the packaging, automotive, and engineering sectors. In Europe, more than 61 million tons of polymers are produced annually [1,2], with the great majority of them being petrochemically-sourced; however, the interest in bio-based materials has flourished over the last few decades, both in academic and industrial fields due to increasing concerns about the depletion of fossil resources and the footprint of synthetic polymers on the environment, as it is estimated that roughly $80 \%$ of synthetic polymers are discarded in landfills or natural recipients [3-5]. In fact, the European Commission supports the synthesis of high added value products based on renewable sources by offering financial support for research, innovation, and industrial upscaling in this field [6].

The conversion of biomass to bio-based monomers, and subsequently polymers by means of biochemical and/or chemical transformations, constitutes the most important route toward the preparation of bio-based plastics like poly(lactic acid) (which, at 
the moment, is the most important bio-based polymer with many applications [7]) and other polymers, owing to the abundance and relatively low cost [8]. Through this path, bio-based forms of conventional plastics such as bio-poly(ethylene terephthalate) and bio-poly(ethylene) [9] may be produced, as well as novel building blocks based on new aromatic precursors, thus reinforcing the transition from a linear to a circular economy [10]. One of the most promising monomers derived from lignin biomass is vanillic acid (VA), which constitutes an oxidation product of vanillin, which is the most commonly produced aroma chemical substance [11,12]. Owing to its structural similarity with terephthalic acid (TPA), VA-based materials are expected to demonstrate comparable thermal and mechanical properties to poly(alkylene terephthalates), which are a series of high performance petrochemically-based thermoplastic polyesters. Furthermore, the continuous progress concerning lignin depolymerization and purification [13-15], combined with the biotechnological production of vanillin [16-19], is defining more sustainable routes towards the preparation of vanillin, thus promoting vanillic acid as an excellent building block for the preparation of fully bio-based polymers.

Poly(ethylene vanillate) (PEV) is a new bio-based alipharomatic polyester produced from vanillic acid that is gaining attention as a potential substitute of the popular poly(ethylene terephthalate) (PET), which is the most common polymeric material in packaging industry. The aforementioned polyesters possess similar alipharomatic structures and subsequently exhibit comparable thermal transitions and nanomechanical properties. Despite its great potential as a packaging material, the synthesis of high molecular weight PEV with high purity and an absence of coloration is still requires investigation.

Catalysts play a key role in the synthesis of polyesters as they affect the reaction and color of the resulting materials [20-23]. More specifically, organometallic compounds of tin, lead, and titanium, such as titanium butoxide (TBT), titanium isopropoxide (TIS), and dibutyltin oxide (DBTO), are known to catalyze the esterification and polycondensation steps. Metal-oxide catalysts (e.g., $\mathrm{TiO}_{2}$ and $\mathrm{GeO}_{2}$ ) are generally preferred for the esterification step, while metal acetates or carbonates (e.g., $\mathrm{Zn}\left(\mathrm{CH}_{3} \mathrm{COO}\right)_{3}$ and $\mathrm{Sb}\left(\mathrm{CH}_{3} \mathrm{COO}\right)_{3}$ ) have been extensively used during polycondensation processes [24-26]. Moreover, it has been proved that the valence of the metal atom and the concentration of the used catalyst alters its activity during the reaction [27]. Finally, toxicity constitutes a crucial parameter upon the selection of the proper polymerization catalyst, especially for the preparation of materials used in the food packaging industry [28-31].

Several attempts to produce PEV using different catalysts have been reported. Mialon et al. polymerized 4-(2-hydroxyethoxy)-3-methoxybenzoic acid using an antimony trioxide $\left(\mathrm{Sb}_{2} \mathrm{O}_{3}\right)$ catalyst, yielding a polyester with an average molecular weight of $5390 \mathrm{~g} \mathrm{~mol}^{-1}$ and a melting temperature of $239^{\circ} \mathrm{C}$ [32]. Furthermore, Gioia et al. reported the preparation of PEV from vanillic acid with ethylene carbonate catalyzed by DBTO $\left(\mathrm{M}_{\mathrm{n}}=4700 \mathrm{~g} \mathrm{~mol}^{-1}\right.$, $\mathrm{T}_{\mathrm{m}}=264{ }^{\circ} \mathrm{C}$ ) [33]. More recently, our research group has investigated the thermal transitions and degradation mechanisms of the abovementioned polyester in the presence of two different catalysts, namely TBT and $\mathrm{Sb}_{2} \mathrm{O}_{3}$, indicating that PEV is a promising alternative to its terephthalate homologues [34]; however, there is no comparative analysis concerning the effect of the catalyst on the molecular weight and the thermal properties of the final polyester.

Herein, a kinetic study of PEV synthesis using three different catalysts is reported for the first time. Titanate catalysts (TBT and TIS) have been selected due to their high efficiency in polyesterification reactions [35], while $\mathrm{Sb}_{2} \mathrm{O}_{3}$ is the most common catalyst for PET production in an industrial context (Figure 1). The evaluation of the reaction progress is monitored using various techniques, including intrinsic viscosity measurement (IV), end group analysis (AV), nuclear magnetic resonance spectroscopy (NMR), Fouriertransformed infrared spectroscopy (FTIR), and differential scanning calorimetry (DSC). The thermal stability of the produced polyesters is investigated with the implementation of evolved gas analysis mass spectrometry (EGA-MS). As coloration in polymeric materials 
affects their field of application, crucial color parameters are defined. Finally, theoretical kinetic studies have been performed to support the experimental observations.<smiles></smiles>

(a)

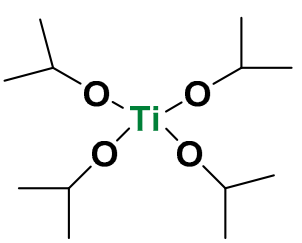

(b)

$$
\mathrm{O}^{-\mathrm{Sb}} \mathrm{CO}^{-\mathrm{Sb}} \text {-Oo }
$$

(c)

Figure 1. Chemical structures of the used catalysts: (a) titanium butoxide (TBT), (b) titanium isopropoxide (TIS), and (c) antimony trioxide $\left(\mathrm{Sb}_{2} \mathrm{O}_{3}\right)$.

\section{Results and Discussion}

\subsection{Effect of Catalysts on the Progress of the Esterification Reaction}

Poly(ethylene vanillate) was produced using a two-step polycondensation method using three different metal-based catalysts, starting from 4-(2-hydroxyethoxy)-3-methoxybenzoic acid, which is a VA-based monomer (Scheme 1). The esterification step was performed for $3 \mathrm{~h}$ at $200{ }^{\circ} \mathrm{C}$, while the polycondensation stage took place at gradually increasing temperatures up to $265^{\circ} \mathrm{C}$ in a vacuum for the preparation of the final polymeric materials. The studied catalysts, i.e., TBT, TIS, and $\mathrm{Sb}_{2} \mathrm{O}_{3}$, were introduced/added in the beginning of the polymerization. Samples were taken from the reaction mixture every $30 \mathrm{~min}$ to observe the progress of the polymerization.<smiles>COc1cc(C(=O)O)ccc1OCCO</smiles>

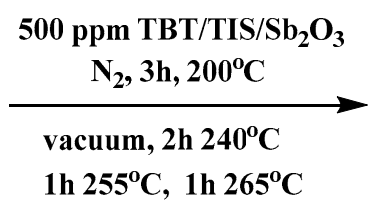<smiles>COCCOc1ccc(C(C)(C)C)cc1OC</smiles>

Scheme 1. Synthesis of poly(ethylene vanillate) polyester with three different catalysts.

The conversion of the carboxylic group $(-\mathrm{COOH})$ of the monomer into the ester group (COOR) of PEV was evaluated using titration and nuclear magnetic resonance spectroscopy (NMR). NMR spectra were recorded in deuterated chloroform/trifluoroacetic acid $\left(\mathrm{CDCl}_{3}\right) /\left(\mathrm{TFA}-\mathrm{d}_{1}\right)(4 / 1 \mathrm{v} / \mathrm{v})$. Indicative examples of ${ }^{1} \mathrm{H} \mathrm{NMR}$ and ${ }^{13} \mathrm{C} \mathrm{NMR}$ spectra of the crude reaction mixture are illustrated in Figure S1 and Figure 2, respectively. In ${ }^{1} \mathrm{H}$ NMR spectra, the methylene protons of the $\mathrm{O}-\mathrm{CH}_{2} \mathrm{~b}-\mathrm{CH}_{2} \mathrm{a}-\mathrm{OH}$ part were selected to monitor the reaction progress. In detail, as a result of the esterification of the hydroxyl group, a shift of the aforementioned protons from $4.42\left(\mathrm{CH}_{2} \mathrm{a}\right)$ and $3.91 \mathrm{ppm}\left(\mathrm{CH}_{2} \mathrm{~b}\right)$ in the monomer to 4.48 and 3.99 ppm in PEV, respectively, is visible. As the reaction time increased, the monomer peaks gradually diminished, and the corresponding polymer peaks dominated the spectrum. Regarding the ${ }^{13} \mathrm{C}$ NMR spectra, a single peak, attributed to the carboxylic acid carbon of the monomer, appeared at 172.0 ppm (carbon a), while the corresponding peak of the ester carbon in PEV appeared at 168.4 ppm (carbon a'). As the reaction proceeded, the intensity of the peak at $172.0 \mathrm{ppm}$ reduced, along with the increase of the peak a'. The conversion after every 30 min interval was calculated from the 
${ }^{13} \mathrm{C}$ NMR spectra by integrating the peaks corresponding to the acid and the ester carbon following Equation (1):

$$
\text { Conversion }(\%)=\frac{a^{\prime}}{a+a \prime}
$$

where $a$ is the integral of the ester carbon and $a$ is the integral of the acid carbon.

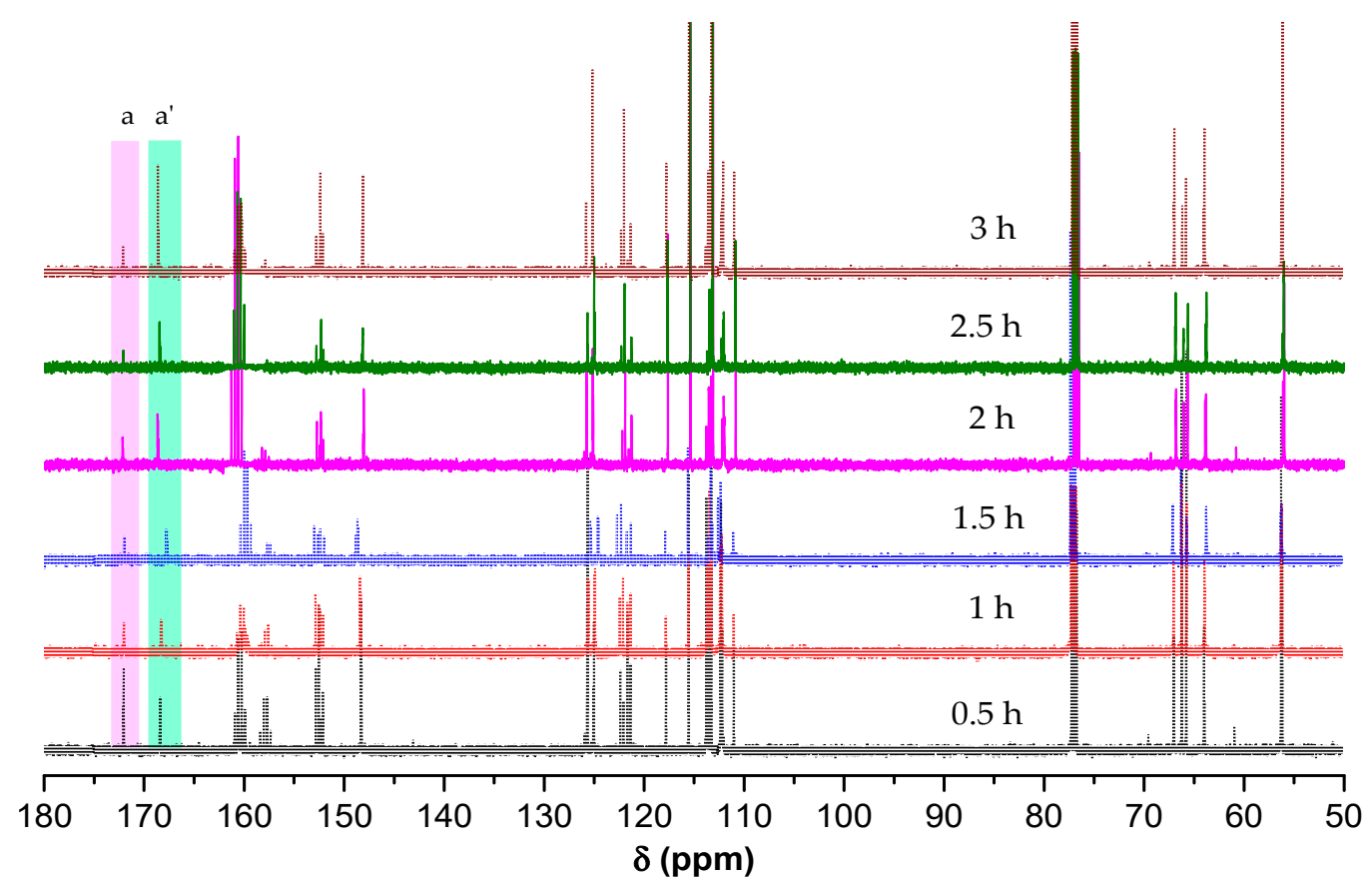

Figure $2 .{ }^{13} \mathrm{C}$ NMR spectra of the crude reaction mixture of the esterification performed at $200{ }^{\circ} \mathrm{C}$ in the presence of TIS.

The assessment of the reaction progress during the esterification step, in the presence of each catalyst, is presented in Figure 3 and Table S1. As shown, the calculated conversion of - $\mathrm{COOH}$ groups using titanium-based catalysts ranged from $80 \%$ to $85 \%$, while the use of $\mathrm{Sb}_{2} \mathrm{O}_{3}$ resulted in a $73 \%$ conversion. These results indicate that TBT and TIS demonstrate greater catalytic activity during the esterification stage of PEV, in accordance with its terephthalate and furan-2,5-dicarboxylate homologues [22,23,27,35].

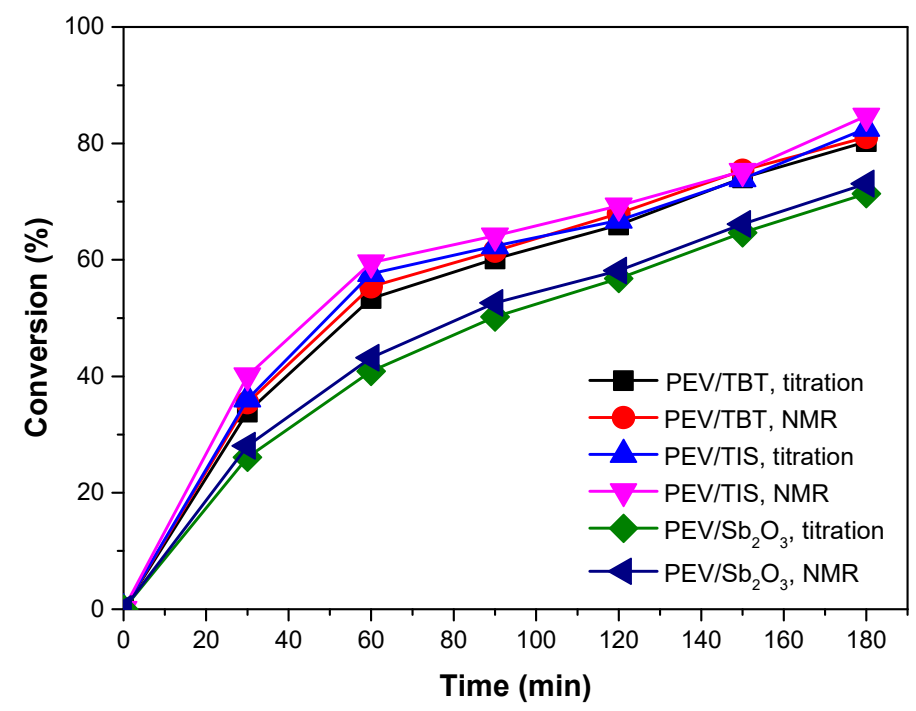

Figure 3. Conversion measured by titration and NMR during the esterification step in the presence of each catalyst. 
The FTIR spectrum of the monomer is displayed in Figure 4, as well as the spectra of the crude reacting mixture at different time intervals during the first stage of the reaction. Briefly, the monomer exhibited a broad absorption band at $3350-3500 \mathrm{~cm}^{-1}$, which can be attributed to the stretching vibrations of the hydroxyl group of the $\mathrm{O}-\mathrm{CH}_{2}-\mathrm{CH}_{2}-\mathrm{OH}$ segment, two separate bands at $2600-3000 \mathrm{~cm}^{-1}$, linked to the stretching vibrations of the bound, through hydrogen bonds, carboxylic $\mathrm{O}-\mathrm{H}$ groups, and a sharp, characteristic band at $1677 \mathrm{~cm}^{-1}$, owing to the $\mathrm{C}=\mathrm{O}$ stretching vibration of the carboxylic acid [36]. Concerning the first $2 \mathrm{~h}$ of the esterification step, two absorption peaks were apparent in the carbonyl area of the spectrum, representing the acid and the ester bond (at 1684 and $1708 \mathrm{~cm}^{-1}$ ) stretching vibrations, respectively. As the reaction proceeded, the first peak diminished, and the formation of a unique peak at $1720 \mathrm{~cm}^{-1}$ was visible. Furthermore, the decrease of the absorption bands at $3350-3500 \mathrm{~cm}^{-1}$ and $2600-3000 \mathrm{~cm}^{-1}$ proved the successful esterification of the hydroxyl group and carboxylic acid. These observations are in agreement with the reaction progress determined by NMR and titrimetry.
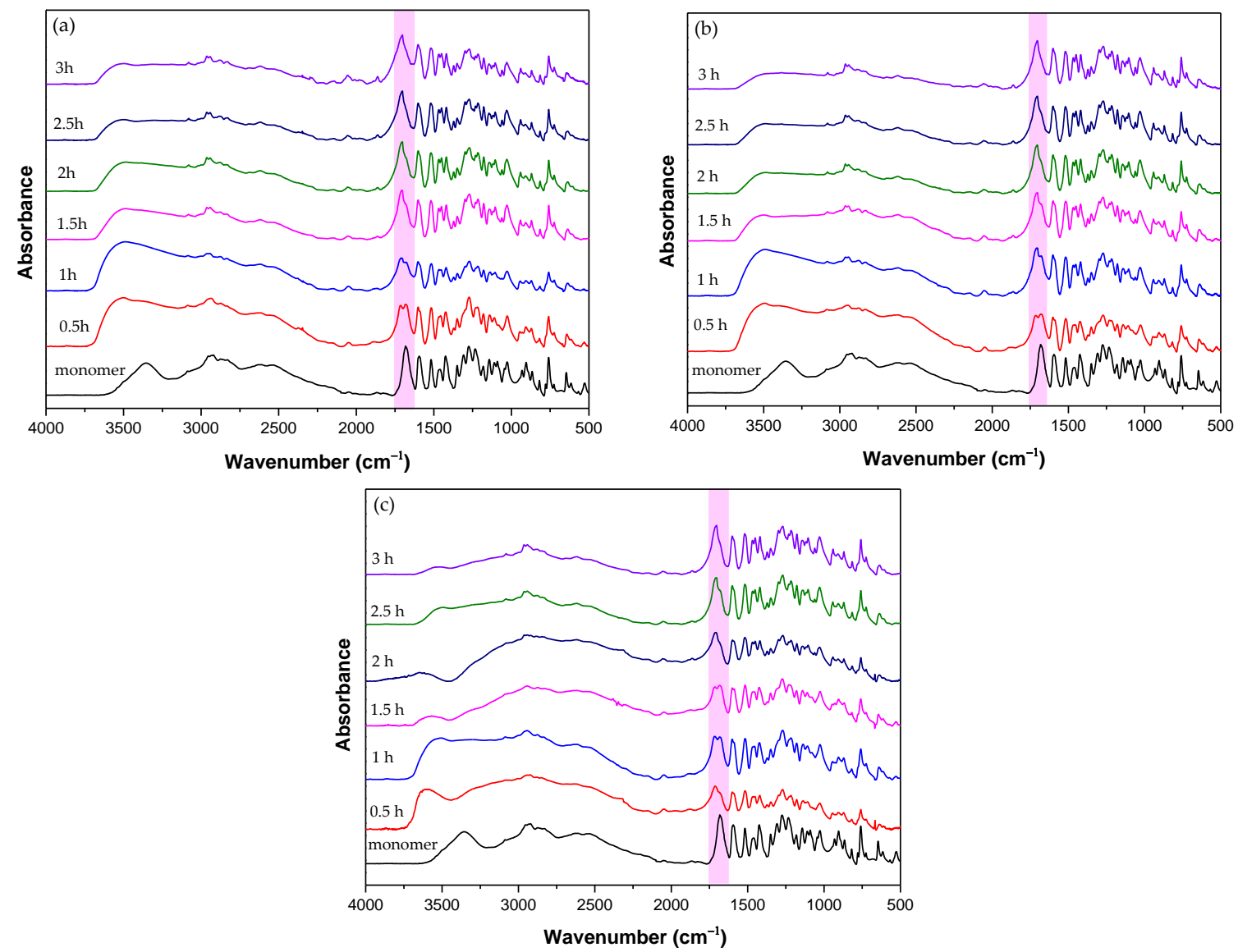

Figure 4. FTIR spectra of the crude reaction mixture during the esterification step at different time intervals in the presence of the (a) TBT, (b) TIS, and (c) $\mathrm{Sb}_{2} \mathrm{O}_{3}$ catalysts.

\subsection{Catalyst Effect on PEV Molecular Weight Increase}

Except for the effect of the catalyst type on the esterification step, emphasis was also given to the evaluation of their activity on the polycondensation stage. The IV of the samples was measured in a phenol/1,1,2,2-tetrachloroethane mixture at $25^{\circ} \mathrm{C}$. As shown in Figure 5 and Figure S2, the samples exhibited different intrinsic viscosity values and subsequently various number average molecular weights, owing to the different reactivity of each catalyst. More specifically, PEV/TBT with $[\eta]=0.27 \mathrm{dL} / \mathrm{g}, \mathrm{PEV} / \mathrm{TIS}$ with $[\eta]=0.29 \mathrm{dL} / \mathrm{g}$, and $\mathrm{PEV} / \mathrm{Sb}_{2} \mathrm{O}_{3}$ with $[\eta]=0.25 \mathrm{dL} / \mathrm{g}$ were prepared. Similarly, the presence of a TIS catalyst resulted in a final polymer where $\mathrm{Mn}=5014 \mathrm{~g} / \mathrm{mol}$, while TBT 
and $\mathrm{Sb}_{2} \mathrm{O}_{3}$ led to polyesters where $\mathrm{Mn}=4375 \mathrm{~g} / \mathrm{mol}$ and $\mathrm{Mn}=3886 \mathrm{~g} / \mathrm{mol}$, respectively. It is evident that the use of titanium-based based catalysts provided higher IV values, and consequently final products with a higher molecular weight. Furthermore, as the reaction progressed, regardless of the catalyst type used, there was an obvious increase of both the IV and Mn values. Overall, the two-step melt polycondensation reaction was interrupted at preselected times to retrieve samples from the reacting mixture. Despite the brevity of each sampling, the interruptions may affect the final IV and Mn values of the produced polyesters.

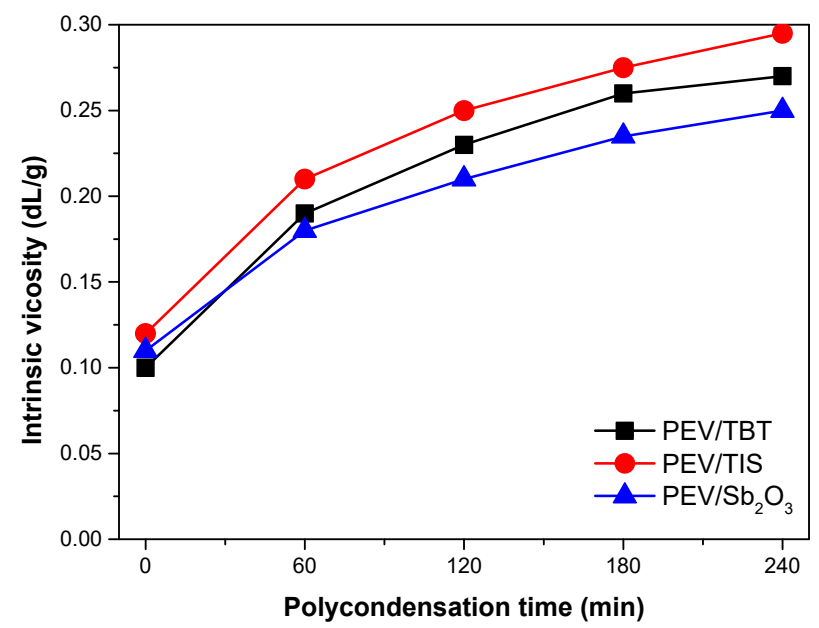

Figure 5. Intrinsic viscosity values at different time intervals during the polycondensation step.

IV measurements were further supported by FTIR analysis. As depicted in Figure S3, in all samples, as the polycondensation proceeded, the band at $3500-3600 \mathrm{~cm}^{-1}$ gradually decreased. This phenomenon can be linked to the reaction between the hydroxyl and carboxyl end groups of $\mathrm{i}$-mers $(\mathrm{i}=2,3,4, \ldots, n)$ towards the formation of polymers; however, the $\mathrm{C}=\mathrm{O}$ stretching band at $1720 \mathrm{~cm}^{-1}$ appeared to not be strongly influenced during the $4-\mathrm{h}$ duration of this step, supporting that the conversion of the $-\mathrm{COOH}$ groups was completed at a high degree during the esterification step.

As thermal transitions and phase changes dominate the processing of polymeric materials and determine the temperature window of this procedure, melting $\left(\mathrm{T}_{\mathrm{m}}\right)$, cold crystallization $\left(\mathrm{T}_{\mathrm{cC}}\right)$, and glass transition $\left(\mathrm{T}_{\mathrm{g}}\right)$ temperatures of the synthesized polyesters during the polycondensation step were measured by DSC. The curves, shown in Figure 6, clearly depict that $T_{g}, T_{c c}$, and $T_{m}$ gradually shift to higher values, following the increase of the molecular weight with increasing polycondensation time and temperature, as analyzed above. In detail, the sample that was prepared in the presence of TIS catalyst after the esterification step exhibits a $\mathrm{T}_{\mathrm{g}}$ value of $73.2^{\circ} \mathrm{C}$, and due to its highly amorphous nature, it exhibits cold crystallization $\left(\mathrm{T}_{\mathrm{cc}}\right)$ at $106.7^{\circ} \mathrm{C}$, while the formed crystals melt at $253.1^{\circ} \mathrm{C}$. Not surprisingly, by increasing the reaction time and temperature $\left(4 \mathrm{~h}, 265^{\circ} \mathrm{C}\right), \mathrm{T}_{\mathrm{g}}, \mathrm{T}_{\mathrm{cc}}$, and $\mathrm{T}_{\mathrm{m}}$ values were observed at higher temperatures. A similar pattern was noticed when the reaction was catalyzed by the other two catalysts (TBT and $\mathrm{Sb}_{2} \mathrm{O}_{3}$ ). Thermal transitions occur at higher temperatures for the polymer prepared in the presence of TIS, where it can thus be concluded that TIS exhibited a higher catalytic activity. The characteristic temperatures of each polymer and at each time interval during the second heating scan are presented in detail in Table 1. 

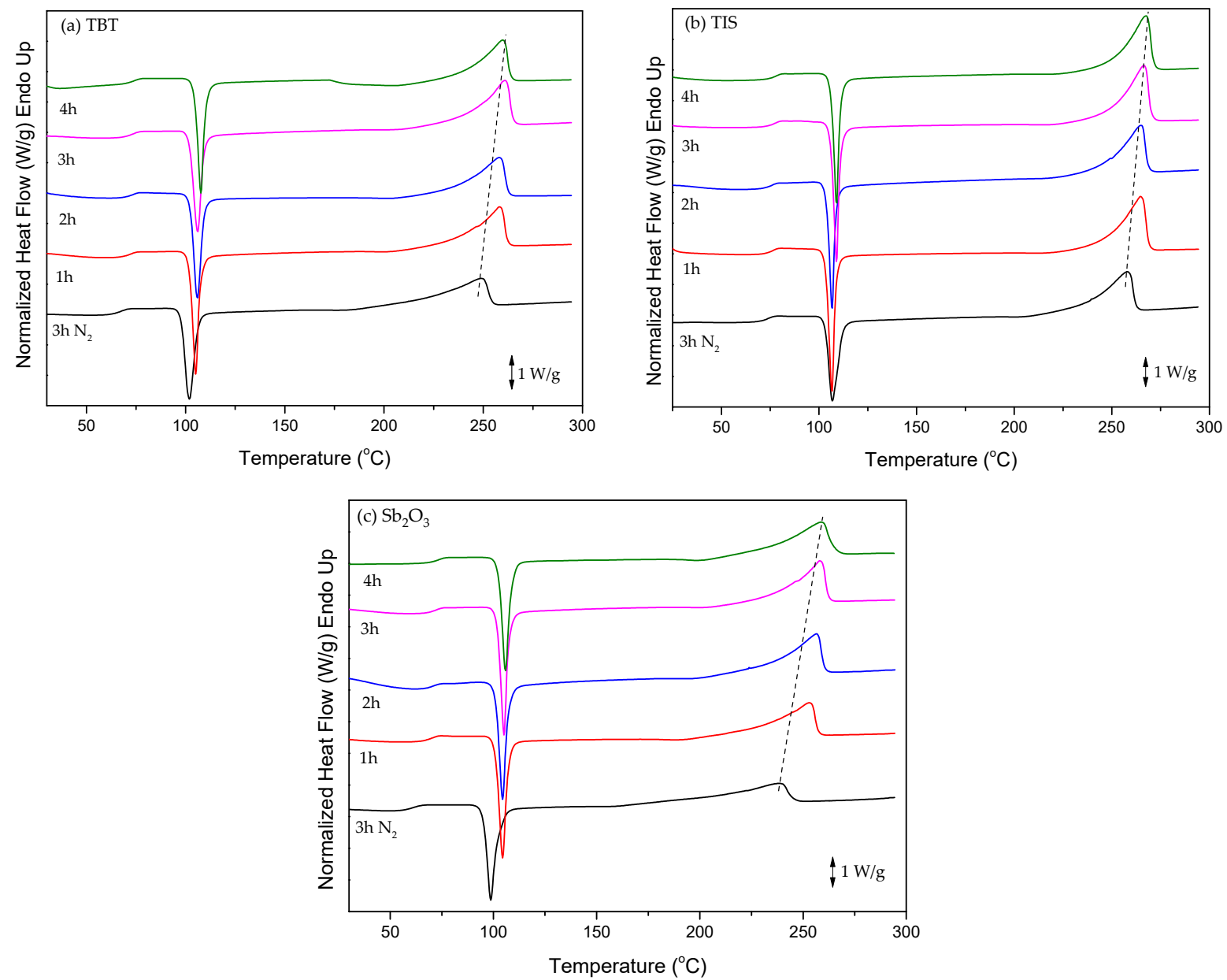

Figure 6. DSC thermograms of the condensation step at different reaction times in the presence of the (a) TBT, (b) TIS, and (c) $\mathrm{Sb}_{2} \mathrm{O}_{3}$ catalysts.

\subsection{Effect of Catalysts on the Thermal Stability of PEV}

The thermal stability of the produced polyesters was evaluated using EGA/MS. As can be observed in Figure 7, the catalyst used appeared to have a small impact on the decomposition temperature peak of the final sample; however, not surprisingly, PEV synthesized with a titanium-based catalyst showed higher thermal stability [29], with a peak (corresponding to the temperature where the largest quantity of degradation products are produced) at $407^{\circ} \mathrm{C}$ and $412{ }^{\circ} \mathrm{C}$ in the presence of TBT and TIS, respectively, while the $\mathrm{Sb}_{2} \mathrm{O}_{3}$-catalyzed material degraded at $405^{\circ} \mathrm{C}$. These observations support the hypothesis of the superior performance of these catalysts in the synthesis of PEV polyesters.

\subsection{Effect of Used Catalysts on PEV Coloration}

Besides their effect on the molecular weight of the final polyesters, the three catalysts also resulted in differences in the coloration of the materials. As shown in Figure 8, the titanium-based catalysts led to reddish-yellowish products, while the use of $\mathrm{Sb}_{2} \mathrm{O}_{3}$ gave a greyish color to the synthesized polymer.

Concerning CIEL $\mathrm{a}^{*} \mathrm{~b}^{*}$ color system values, in all three polymers, there was a relatively large decrease in lightness $\left(\Delta \mathrm{L}^{*}=10\right)$ after the first hour of the polycondensation reaction, followed by a gradual one as time increased. Furthermore, the $\mathrm{a}^{*}$ and $\mathrm{b}^{*}$ values (linked to the green-red and blue-yellow axes, respectively) of each sample were also calculated (Figure 9b,c), demonstrating that TBT and TIS offered stronger red-yellow hues to the corresponding materials in comparison with $\mathrm{Sb}_{2} \mathrm{O}_{3}$. Finally, the $\mathrm{K} / \mathrm{S}$ fraction, which is connected to the concentration of the color on the polyester, was determined (Figure 9d). As 
can be seen, samples that were synthesized with the presence of $\mathrm{Sb}_{2} \mathrm{O}_{3}$ catalyst possessed higher concentrations of color on their surface.

Table 1. Thermal characteristics, including the glass transition $\left(T_{g}\right)$, cold crystallization $\left(T_{c c}\right)$, melting point $\left(T_{m}\right)$, and crystallization temperature $\left(T_{c}\right)$ of melt-quenched PEV samples when using different catalysts.

\begin{tabular}{|c|c|c|c|}
\hline \multicolumn{4}{|c|}{ PEV/TBT } \\
\hline \multirow{2}{*}{ Time (min) } & \multicolumn{3}{|c|}{ Melt-Quenched } \\
\hline & $\mathrm{T}_{\mathrm{g}}\left({ }^{\circ} \mathrm{C}\right)$ & $\mathrm{T}_{\mathrm{cc}}\left({ }^{\circ} \mathrm{C}\right)$ & $\mathrm{T}_{\mathrm{m}}\left({ }^{\circ} \mathrm{C}\right)$ \\
\hline 0 & 66.7 & 101.9 & 248.9 \\
\hline 60 & 72.4 & 105.9 & 258 \\
\hline 120 & 72.6 & 106.1 & 259.7 \\
\hline 180 & 73 & 106.6 & 260.2 \\
\hline 240 & 73.5 & 107.7 & 260.9 \\
\hline \multicolumn{4}{|c|}{ PEV/TIS } \\
\hline Time (min) & $\mathrm{T}_{\mathrm{g}}\left({ }^{\circ} \mathrm{C}\right)$ & $\mathrm{T}_{\mathrm{cc}}\left({ }^{\circ} \mathrm{C}\right)$ & $\mathrm{T}_{\mathrm{m}}\left({ }^{\circ} \mathrm{C}\right)$ \\
\hline 0 & 73.2 & 106.7 & 253.1 \\
\hline 60 & 75.2 & 106.7 & 264.6 \\
\hline 120 & 75.9 & 106.8 & 264.8 \\
\hline 180 & 76.7 & 108.8 & 266.5 \\
\hline 240 & 77.3 & 109.1 & 267.5 \\
\hline \multicolumn{4}{|c|}{$\mathrm{PEV} / \mathrm{Sb}_{2} \mathrm{O}_{3}$} \\
\hline Time (min) & $\mathrm{T}_{\mathrm{g}}\left({ }^{\circ} \mathrm{C}\right)$ & $\mathrm{T}_{\mathrm{cc}}\left({ }^{\circ} \mathrm{C}\right)$ & $\mathrm{T}_{\mathrm{m}}\left({ }^{\circ} \mathrm{C}\right)$ \\
\hline 0 & 61.1 & 98.7 & 238.6 \\
\hline 60 & 69.1 & 104.4 & 253 \\
\hline 120 & 70.2 & 104.5 & 256.4 \\
\hline 180 & 72.3 & 106 & 257.8 \\
\hline 240 & 72.4 & 106.2 & 258.9 \\
\hline
\end{tabular}

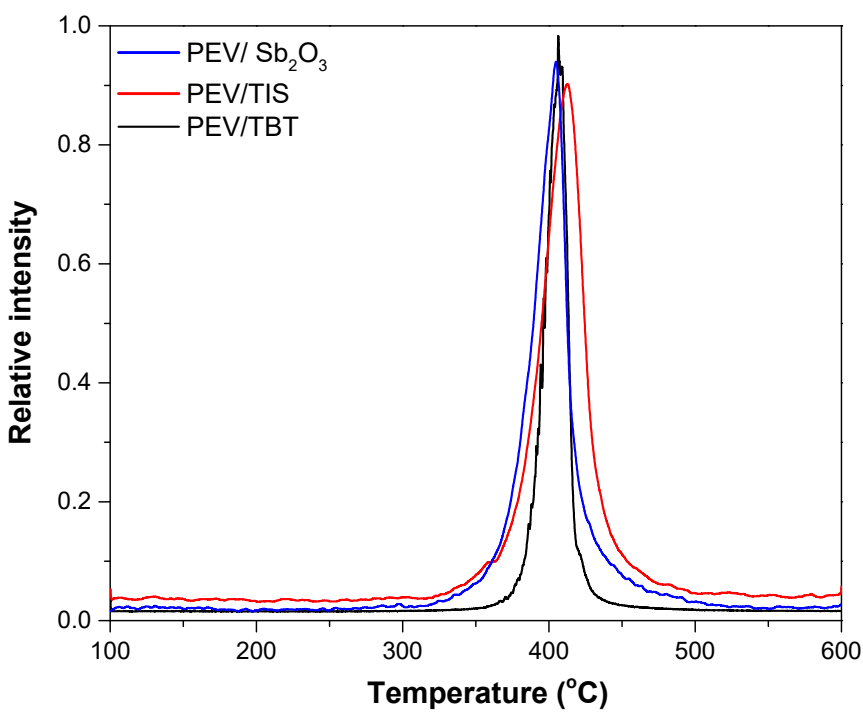

Figure 7. EGA pyrograms of PEV in the presence of each catalyst. 


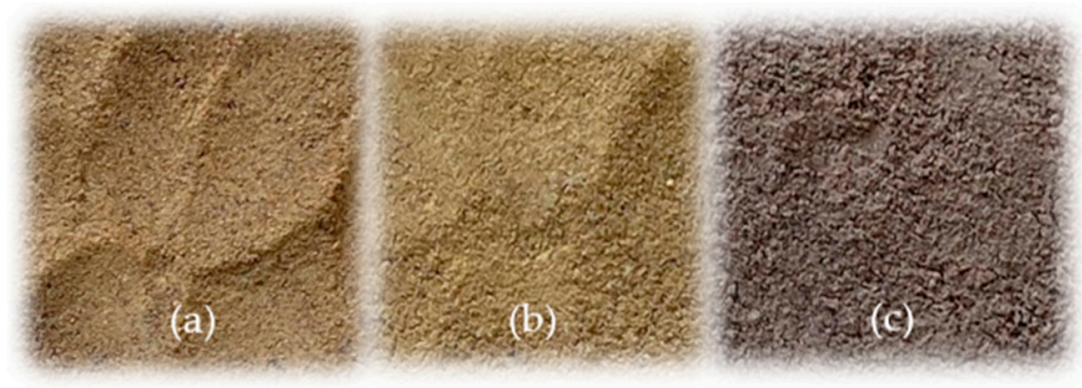

Figure 8. Appearances of the final (a) PEV/TBT, (b) PEV/TIS, and (c) PEV/ $\mathrm{Sb}_{2} \mathrm{O}_{3}$ samples after $4 \mathrm{~h}$ of melt polycondensation.
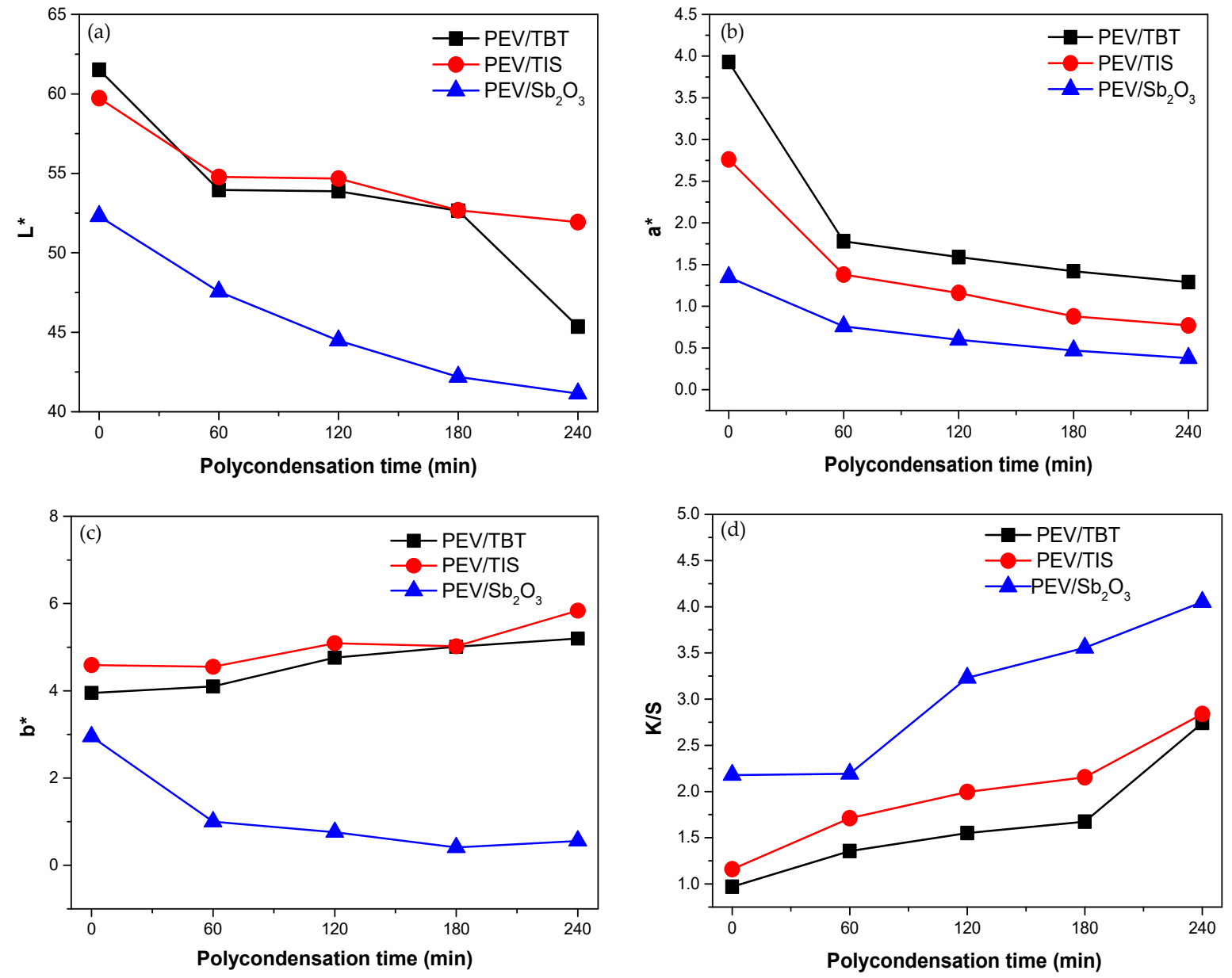

Figure 9. Variation of (a) $\mathrm{L}^{*},(\mathbf{b}) \mathrm{a}^{*},(\mathbf{c}) \mathrm{b}^{*}$, and (d) K/S values of PEV samples prepared with different catalysts and polycondensation times.

Overall, the formation of the colored polycondensation products can be attributed to prolonged heating at a temperature above $240{ }^{\circ} \mathrm{C}$. At these temperatures, a high degree of yellowing can be caused either due to the possible decarboxylation of the starting monomer [34] or due to the potential formation of organic contaminants during the polymerization. Moreover, the grey discoloration of PEV in the case of $\mathrm{Sb}_{2} \mathrm{O}_{3}$ catalysts may be attributed to the reduction of $\mathrm{Sb}^{+3}$ to elementary $\mathrm{Sb}^{0}$ in the presence of carbon oxides. These observations are in agreement with the effect of the aforementioned catalysts on the discoloration of PET and poly(ethylene furan-2,5-dicarboxylate) (PEF). [37-39]. 


\subsection{Reaction Kinetic Analysis}

In general, there are three approaches to model the kinetics of esterification/polycondensation reactions. In order of increasing complexity, they are (i) the simple empirical laws for the rate of decrease of reactant concentration (e.g., in [40]); (ii) the functional group models (e.g., in [41]) which are restricted to the description of the evolution of the active molecular groups (e.g., hydroxyl and carboxyl in the present case); and (iii) detailed molecular species models, which describe in detail all the reaction occurring in the process. The number of unknown kinetic parameters increases from (i) to (iii). The physical meanings of parameters also increase as we move from empirical (i.e., in (i)) to detailed (i.e., in (iii)) models. Here, a combination of approaches (ii) and (iii) will be followed.

The particular problem at hand is linear chain polymerization with a single monomer. Actually, the same reaction occurs in both esterification and transesterification steps. The detailed kinetic model for the evolution of the concentration of the i-mers (molecules consisted of i-primary units) is $\left(i=1,2, \ldots, N_{\max }\right)$

$$
\frac{d C_{i}}{d t}=\frac{1}{2} \sum_{j=1}^{i} K_{i-j, j} C_{i-j} C_{j}-C_{i} \sum_{j=1}^{N_{\max }} K_{i, j} C_{j}
$$

where $N_{\max }$ corresponds to the larger i-mer in the system and $K_{i, j}$ is the reaction constant for the reaction between an i-mer and a j-mer. The above equation is used in an approximate way to model the esterification step. The conversion of a functional group is experimentally measured in this step. This conversion corresponds to the loss of monomers from the system (i.e., evolution of variable $C_{1}$ ). It can be assumed that during esterification the main mechanism for monomer loss is the reaction between monomers. In reality, some larger molecules are formed, but the concentrations are too low and the reaction rates of monomers with them are negligible. In such a situation, Equation (2) is transformed to the following form:

$$
\frac{d C_{1}}{d t}=-k C_{1}^{2}
$$

This is a simple second-order reaction (with $k=K_{1,1}$ ). This equation is integrated and transformed to give the percentage conversion $\mathrm{R}$ as $R=100\left(1-\frac{1}{1+k C_{o} t}\right)$, where $C_{o}$ is the initial concentration of the reactant. To exploit the experimental conversions measured by both techniques employed in the present work their average values are considered. Then, the above expression for $\mathrm{R}$ is fitted to the average conversion data. The results of the fittings are presented in Figure 10.

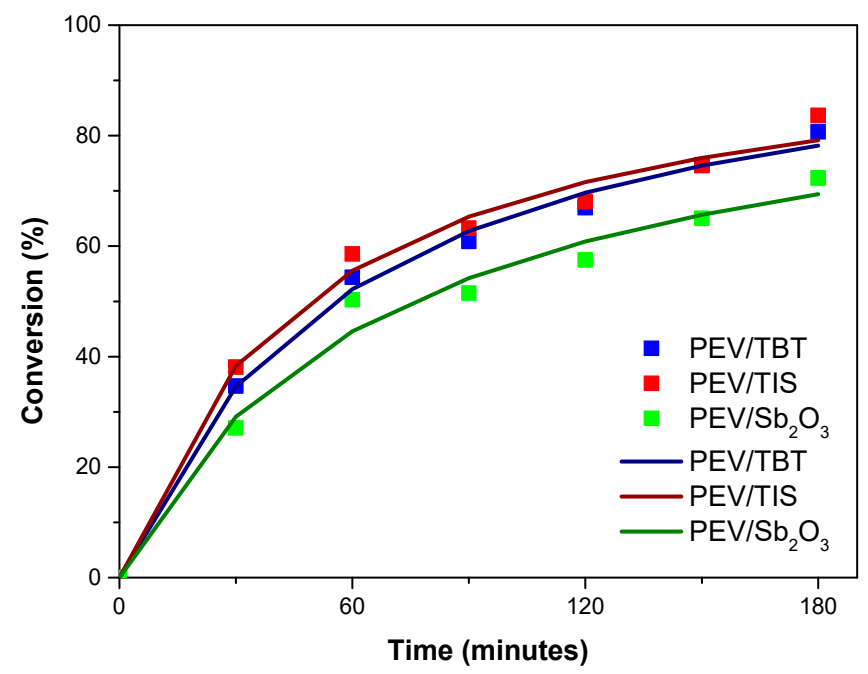

Figure 10. Comparison of experimental (symbols) and model (continuous lines) conversions of the esterification reaction. The experimental data are averaged from both techniques. 
The values found for the single fitting parameter $k C_{o}$ are $0.018,0.02,0.0137 \mathrm{~min}^{-1}$ for the catalysts TBT, TIS, and $\mathrm{Sb}_{2} \mathrm{O}_{3}$, respectively. Considering that $\mathrm{C}_{o}$ is the same for all catalysts, the esterification reaction constant appears to be largest for TIS, followed by TBT, leaving $\mathrm{Sb}_{2} \mathrm{O}_{3}$ as the least effective catalyst. The validity of the approximation of the system by Equation (3) is confirmed by assuming the reaction order exponent as a second fitting parameter. The fitting with two parameters led to values of the exponent very close to two.

The next step was the examination of the polycondensation reaction. The reactions in the presence of the three catalysts started from different initial conditions (i.e., average molecular weight) as a consequence of the different extents of preceding esterification reactions. To eliminate the effect of initial conditions, the normalized molecular weight $M / M_{o}$ evolution is presented in Figure 11, where $M$ is the average molecular weight in the reaction mixture and $M_{o}$ denotes its value at the beginning of polycondensation step.

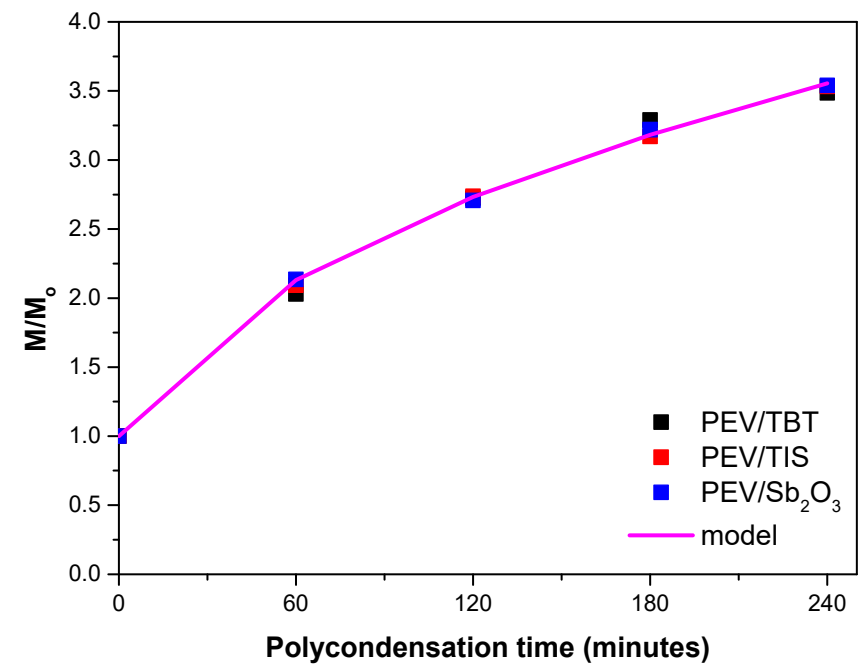

Figure 11. Experimental normalized average molecular weight (symbols) and the corresponding model (continuous line).

It is very interesting that the evolution curves of $M / M_{o}$ practically coincided for the three catalysts, implying that the performances of the three catalysts for polycondensation were similar to each other. To model the (unique for all catalysts) polycondensation kinetics, the system (2) of $N_{\max }$ ordinary differential equations must be numerically integrated. A choice of the kinetic function $K_{i, j}$ is needed. It is expected that the motion of the polymer chains is inhibited as their molecular weight increases so the choice $K_{i, j} \propto\left(i^{-\lambda}+j^{-\lambda}\right)$ (where $\lambda$ is a positive parameter) is a reasonable one. There are no experimental data for the complete molecular weight distribution, but only for its average value so the system is solved approximately using the monodisperse method of moments to give the following simple equation for the evolution of the ratio $M / M_{o}$ (details of the derivation can be found in [22]):

$$
\frac{M}{M_{o}}=\left(1+(1+\lambda) K_{o} t\right)^{1 /(1+\lambda)}
$$

Data fitting (shown in Figure 11) was achieved using the values $\lambda=2.5$ and $K_{o}=0.037 \mathrm{~min}^{-1}$ (for all the catalysts). The value $\lambda=2.5$ implies a large reduction of reaction rate as the chain length of the reactant increases. This is due to a combination of reduced molecule mobility (i.e., diffusivity) and increased mixture viscosity, as the size of the molecules increases. 


\section{Materials and Methods}

\subsection{Materials}

Vanillic acid (VA, purum 99\%) was supplied by J \& K Scientific (GmbH, Pforzheim, Germany). Sodium iodide ( $>99 \%)$, used in the synthesis of the monomer, was purchased by Acros Organics N.V. (Geel, Belgium). Furthermore, the 2-chloroethanol ( $>99 \%)$, titanium butoxide $\left(\mathrm{Ti}(\mathrm{OBu})_{4}\right)$, titanium isopropoxide $\left(\mathrm{Ti}(\mathrm{iOPr})_{4}\right)$, and antimony trioxide $\left(\mathrm{Sb}_{2} \mathrm{O}_{3}\right)$ (analytic grade) catalysts were provided by Sigma-Aldrich Co (Chemie GmbH, Steinheim, Germany). Phenol (99+\%), and 1,1,2,2-tetrachloroethane (98+\%), utilized as a mixture for intrinsic viscosity measurements, were purchased from Alfa Aesar (Kandel, Germany). All other solvents and materials used were of an analytical grade.

\subsection{Synthesis of 4(2-Hydroxyethoxy)-3-Methoxybenzoic Acid}

In short, $33.6 \mathrm{~g}$ of vanillic acid $(0.20 \mathrm{~mol})$ and $12 \mathrm{~g}$ of sodium iodide $(0.08 \mathrm{~mol})$ were dissolved in an aqueous potassium hydroxide solution $(33.75 \mathrm{~g}(0.6 \mathrm{~mol})$ in $260 \mathrm{~mL}$ of water). Then, $17.7 \mathrm{~g}(0.22 \mathrm{~mol})$ of 2-chloroethanol, dissolved in $520 \mathrm{~mL}$ of ethanol, was added dropwise over $4 \mathrm{~h}$ at $100{ }^{\circ} \mathrm{C}$, after having been degassed by $\mathrm{N}_{2}$ bubbling. The reacting mixture was refluxed and $6.0 \mathrm{~g}$ of 2-chloroethanol was added approximately every $12 \mathrm{~h}$. After 4 days, the obtained mixture was concentrated using a rotary evaporator, and the residue was diluted in water. The aqueous solution was washed with ether and acidified with aqueous hydrochloric acid solution. The precipitated solid was separated by filtration and purified by two subsequent recrystallizations in ethanol to obtain the product in $64 \%$ yield [34].

\subsection{Synthesis of Poly(Ethylene Vanillate) Polyesters}

The synthesis of PEV polyesters was carried out via a two-stage melt polycondensation procedure in a glass batch reactor according to previous studies by our research group [42]. First, $8 \mathrm{~g}$ of 4-(2-hydroxyethoxy)-3-methoxybenzoic acid was charged into the reaction tube of the polycondensation apparatus. Then, $500 \mathrm{ppm}(0.5 \mathrm{~mL})$ of TBT, TIS, or $\mathrm{Sb}_{2} \mathrm{O}_{3}$ was subsequently added in the polycondensation reactor and the apparatus was subsequently evacuated and filled with $\mathrm{N}_{2}$ three times to remove oxygen. The reacting mixture was heated at $200{ }^{\circ} \mathrm{C}$ under $\mathrm{N}_{2}$ flow $(50 \mathrm{~mL} / \mathrm{min}$ ) for $3 \mathrm{~h}$. At 30 min time periods, samples were collected from the reaction mixture for analysis. During the second stage, a vacuum (5.0 Pa) was progressively applied over $20 \mathrm{~min}$ and the temperature was gradually increased to $240{ }^{\circ} \mathrm{C}$ while the stirring speed was increased from 360 to $750 \mathrm{rpm}$ over an hour. The reacting mixture was heated for $2 \mathrm{~h}$ at $240^{\circ} \mathrm{C}$ and the temperature was further increased to $255^{\circ} \mathrm{C}$ and $265^{\circ} \mathrm{C}$ for $1 \mathrm{~h}$ each time. Finally, the resulting materials were milled and washed with methanol. Samples after 1, 2, 3, and $4 \mathrm{~h}$ of the second step were gathered and characterized using various techniques.

\subsection{Polyesters' Characterization}

\subsubsection{Acid Value Measurements}

The carboxyl end group content was defined by titration with a potassium hydroxide methanolic solution $(0.1 \mathrm{M})$ and phenol red as an indicator. For each sample, the titration was repeated in triplicate and the mean value was estimated. The acid value (AV) represents the unreacted acid groups, and it is defined as the milliliters of potassium hydroxide solution required to neutralize one gram of sample. The $\mathrm{AV}$ of the resulted polyesters was determined based on Equation (5):

$$
A V=\frac{C \times V \times 56.11}{m}
$$

where $V$ is the volume of $\mathrm{KOH}$ solution consumed (in $\mathrm{mL}$ ); $C$ is the concentration of the $\mathrm{KOH}$ solution (in M); $m$ stands for the mass of the sample (in grams); and 56.11 is potassium hydroxide molar mass (in $\mathrm{g} / \mathrm{mol}$ ). 
Furthermore, the conversion of the monomer to polyester was subsequently calculated with the implementation of Equation (6):

$$
\text { Conversion }(\%)=\frac{A V_{0}-A V_{t}}{A V_{0}}
$$

where $A V_{0}$ is the initial $A V$ and $A V_{t}$ is the $A V$ value at each sampling interval.

\subsubsection{Nuclear Magnetic Resonance (NMR)}

NMR spectra were recorded in deuterated chloroform/trifluoroacetic acid $\left(\mathrm{CDCl}_{3}\right) /(\mathrm{TFA}-$ $\left.\mathrm{d}_{1}\right)(4 / 1 v / v)$, using an Agilent 500 spectrometer (Agilent Technologies, Santa Clara, CA, USA) at room temperature. Spectra were calibrated utilizing the residual solvent peaks.

\subsubsection{Intrinsic Viscosity Measurements (IV)}

The intrinsic viscosity was measured with an Ubbelohde viscometer (Schott Gerate GMBH, Hofheim, Germany) at $25^{\circ} \mathrm{C}$ in a phenol and 1,1,2,2-tetrachloroethane $(60 / 40$, $w / w)$ solution. To reach complete dissolution, the sample was heated in the solvent mixture at $70{ }^{\circ} \mathrm{C}$ for $20 \mathrm{~min}$. After cooling, the solution was filtered through a disposable Teflon filter, to eliminate possible solid residues. The calculation of the intrinsic viscosity values of the produced polyesters performed applying the Solomon-Cuita equation (Equation (7)) for a single point measurement:

$$
[\eta]=\frac{\left[2\left\{\frac{t}{t_{0}}-\ln \left(\frac{t}{t_{0}}\right)-1\right\}\right]^{\frac{1}{2}}}{c}
$$

where $c$ is the solution concentration, $t$ is the flow time of the solution and $t_{0}$ is the flow time of the solvent. The experiment was performed three times and the average value was estimated.

\subsubsection{Molecular Weight}

Intrinsic viscosity values $[\eta]$ were used to calculate the number average molecular weight (Mn) of the PEV samples, using the Berkowitz equation (Equation (8)), as it was modified in our previous work [43]:

$$
M n=3.29 \times 10^{4}[\eta]^{1.54}
$$

\subsubsection{Fourier-Transformed Infrared Spectroscopy (FTIR)}

FTIR spectra of the produced polyesters were obtained by FTIR-2000 (Perkin Elmer, Waltham, MA, USA). A small amount of each sample was triturated with a proper amount of potassium bromide $(\mathrm{KBr})$ and the disks were formed under pressure. All spectra were collected in the range from 4000 to $500 \mathrm{~cm}-1$ using a resolution of $4 \mathrm{~cm}-1$ and 32 co-added scans. The presented spectra were further baseline corrected, normalized, and converted into an absorbance mode.

\subsubsection{Differential Scanning Calorimetry (DSC)}

Differential scanning calorimetry measurements were performed using a PerkinElmer Pyris Diamond DSC (PerkinElmer Corporation, Waltham MA, USA), updated to the DSC 8500 level, combined with an Intracooler 2P cooling accessory, calibrated with pure indium and zinc standards. Samples of $5 \pm 0.1 \mathrm{mg}$ sealed in aluminum pans were applied for assessing the thermal behavior of the produced polymers. All samples were initially heated at $20{ }^{\circ} \mathrm{C} / \mathrm{min}$ up to $300{ }^{\circ} \mathrm{C}$ and held at this temperature for three minutes to erase any previous thermal history. The glass transition $\left(\mathrm{T}_{\mathrm{g}}\right)$ and cold crystallization $\left(\mathrm{T}_{\mathrm{cc}}\right)$ temperatures were measured by performing a heating scan of the melt-quenched samples at $20^{\circ} \mathrm{C} / \mathrm{min}$. 


\subsubsection{Color Measurements}

Color measurements were performed using a Datacolor Spectraflash SF600 plus CT UV reflectance colorimeter (Datacolor, Marl, Germany) with the implementation of the D65 illuminant, a $10^{\circ}$ standard observer with the UV component excluded and the specular component included. In each case, five measurements were performed using a special holder (Datacolor) and the mean values were calculated. The color values were calculated via the CIE L*a*b* color space system and the modified CIELCH system [44]. In this system, $L^{*}$ represents the lightness $\left(L^{*}=0\right.$, black, $L^{*}=100$, white). As depicted in Figure 12 , the $a^{*}$ value corresponds to the green-red axis, where negative $a^{*}$ values indicate green and positive $a^{*}$ values indicate red hues. The $b^{*}$ value represents the blue-yellow axis, where negative $b^{*}$ values indicate blue and positive $b^{*}$ values indicate yellow hues.

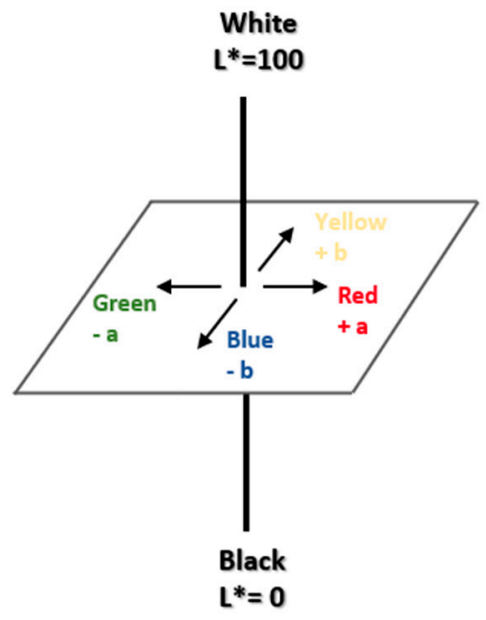

Figure 12. Illustration of CIE $L^{*} a^{*} b^{*}$ color space system.

Furthermore, the fraction $\mathrm{R} / \mathrm{S}$, linked to the concentration of the color on the polyester, was determined following Equation (5):

$$
\frac{K}{S}=\frac{(1-R)^{2}}{2 R}
$$

where $K$ is the absorbance coefficient, $S$ stands for the scattering coefficient, and $R$ is the percent reflectance of each sample.

\subsubsection{Evolved Gas Analysis Mass Spectroscopy (EGA/MS)}

For the performance of the Py-GC/MS analysis of the resulting polyesters, a very small quantity of the material has been set primarily into the "Double-Shot" EGA/PY3030D Pyrolyzer (Frontier Laboratories Ltd., Fukushima Japan) with a CGS-1050Ex (Kyoto, Japan) carrier gas selector. For evolved gas analysis (EGA), the furnace temperature was programmed from $100{ }^{\circ} \mathrm{C}$ to $600{ }^{\circ} \mathrm{C}$ with a heating rate of $20^{\circ} \mathrm{C} / \mathrm{min}$, using He as the purge gas and air as the cooling gas. The GC oven temperature was set at $300^{\circ} \mathrm{C}$ for $25 \mathrm{~min}$. The pyrolyzates were separated using the temperature programmed capillary column of a Shimadzu QP-2010 Ultra Plus (Shimadzu, Kioto, Japan) gas chromatograph and were analyzed by the mass spectrometer MS-QP2010SE of Shimadzu (Shimadzu, Kioto, Japan) at $70 \mathrm{eV}$. For the mass spectrometer, the following conditions were used: ion source heater at $200{ }^{\circ} \mathrm{C}$, interface temperature at $320^{\circ} \mathrm{C}$, vacuum of $10-4-100 \mathrm{~Pa}, \mathrm{~m} / \mathrm{z}$ range of $45-500 \mathrm{amu}$, and scan speed of $10,000 \mathrm{u} / \mathrm{s}$.

\section{Conclusions}

Within this study, the efficiency of three different metal-based catalysts (TBT, TIS, and $\mathrm{Sb}_{2} \mathrm{O}_{3}$ ) during two-step melt polycondensation of PEV was examined for the first time. The evolution of the esterification step was investigated using various techniques, such as NMR, 
end group analysis, and FTIR. Based on the acquired results, titanium-based catalysts seem to exhibit higher catalytic activity. In the second stage of the reaction, the efficiency of the used catalysts followed the same pattern, resulting in polyesters with higher molecular weights and subsequently superior thermal transitions (higher $\mathrm{T}_{\mathrm{g}}, \mathrm{T}_{\mathrm{cc}}$, and $\mathrm{T}_{\mathrm{m}}$ values), as well as elevated thermal stability. Since coloration in materials plays an important role toward their future applications, color measurements were also performed, proving that the reaction time and temperature strongly affect the discoloration of the final materials, resulting in reddish-yellowish products in the case of titanium-based catalysts and a greyish polymer when in the presence of $\mathrm{Sb}_{2} \mathrm{O}_{3}$. Finally, theoretical kinetic studies were carried out and rate constants for the reactions that took place in each step were calculated, indicating that TIS possesses superior catalytic activity during the esterification stage, while all three catalysts exhibited similar behavior during the polycondensation process.

Supplementary Materials: The following are available online at https:/ / www.mdpi.com/article/10 $.3390 /$ catal11070822/s1. Figure S1: 1H NMR spectra of the crude reaction mixture of the esterification performed at $200{ }^{\circ} \mathrm{C}$, in the presence of TIS. Table S1: Conversions obtained/observed in the presence of TBT, TIS and Sb2O3 catalysts. Figure S2: Evaluation of number average molecular weight at different time intervals during the polycondensation step. Figure S3: FTIR spectra of the crude reaction mixture during the polycondensation step at different time intervals in the presence of (a) TBT, (b) TIS and (c) Sb2O3 catalyst.

Author Contributions: Investigation, methodology, formal analysis, writing-original draft E.X.; investigation, methodology, formal analysis A.Z. and Z.T.; methodology, formal analysis M.K.; supervision, writing - review and editing D.N.B. and G.Z.P. All authors have read and agreed to the published version of the manuscript.

Funding: This research received no external funding.

Institutional Review Board Statement: Not applicable.

Informed Consent Statement: Not applicable.

Data Availability Statement: Data are provided within the article.

Acknowledgments: This publication is based upon work from COST Action FUR4Sustain, CA18220, supported by COST (European Cooperation in Science and Technology).

Conflicts of Interest: The authors declare no conflict of interest.

\section{References}

1. PlasticsEurope (2019) Plastics-the Facts 2019. An Analysis of European Plastics Production, Demand and Waste Data. Available online: https:/ / www.plasticseurope.org/en/resources/publications/1804-plastics-facts-2019 (accessed on 15 May 2021).

2. Filho, W.L.; Salvia, A.L.; Bonoli, A.; Saari, U.A.; Voronova, V.; Klõga, M.; Kumbhar, S.S.; Olszewski, K.; De Quevedo, D.M.; Barbir, J. An assessment of attitudes towards plastics and bioplastics in Europe. Sci. Total Environ. 2021, 755, 142732. [CrossRef]

3. Chen, Y.; Li, T.; Hu, H.; Ao, H.; Xiong, X.; Shi, H.; Wu, C. Transport and fate of microplastics in constructed wetlands: A microcosm study. J. Hazard. Mater. 2021, 415, 125615. [CrossRef]

4. Geyer, R.; Jambeck, J.R.; Law, K.L. Production, use, and fate of all plastics ever made. Sci. Adv. 2017, 3, 25-29. [CrossRef]

5. Yang, L.; Zhang, Y.; Kang, S.; Wang, Z.; Wu, C. Science of the Total Environment Microplastics in soil: A review on methods, occurrence, sources, and potential risk. Sci. Total Environ. 2021, 780, 146546. [CrossRef]

6. European Commission. A Sustainable Bioeconomy for Europe: Strengthening the Connection between Economy, Society and the Environment. COM(2018) 673 Final; European Union: Brussels, Belgium, 2018.

7. Balla, E.; Daniilidis, V.; Karlioti, G.; Kalamas, T.; Stefanidou, M.; Bikiaris, N.D.; Vlachopoulos, A.; Koumentakou, I.; Bikiaris, D.N. Poly(lactic Acid): A Versatile Biobased Polymer for the Future with Multifunctional Properties—From Monomer Synthesis, Polymerization Techniques and Molecular Weight Increase to PLA Applications. Polymers 2021, 13, 1822. [CrossRef] [PubMed]

8. Storz, H.; Vorlop, K.D. Bio-based plastics: Status, challenges and trends. Appl. Agric. For. Res. 2013, 63, 321-332.

9. Neaţu, F.; Culică, G.; Florea, M.; Parvulescu, V.I.; Cavani, F. Synthesis of Terephthalic Acid by p-Cymene Oxidation using Oxygen: Toward a More Sustainable Production of Bio-Polyethylene Terephthalate. ChemSusChem 2016, 9, 3102-3112. [CrossRef] [PubMed]

10. Poveda-Giraldo, J.A.; Solarte-Toro, J.C.; Cardona Alzate, C.A. The potential use of lignin as a platform product in biorefineries: A review. Renew. Sustain. Energy Rev. 2021, 138, 110688. [CrossRef]

11. Fache, M.; Boutevin, B.; Caillol, S. Vanillin, a key-intermediate of biobased polymers. Eur. Polym. J. 2015, 68, 488-502. [CrossRef] 
12. Fache, M.; Darroman, E.; Besse, V.; Auvergne, R.; Caillol, S.; Boutevin, B. Vanillin, a promising biobased building-block for monomer synthesis. Green Chem. 2014, 16, 1987-1998. [CrossRef]

13. Gomes, E.D.; Rodrigues, A.E. Lignin biorefinery: Separation of vanillin, vanillic acid and acetovanillone by adsorption. Sep. Purif. Technol. 2019, 216, 92-101. [CrossRef]

14. Mota, M.I.F.; Pinto, P.C.R.; Loureiro, J.M.; Rodrigues, A.E. Recovery of Vanillin and Syringaldehyde from Lignin Oxidation: A Review of Separation and Purification Processes. Sep. Purif. Rev. 2016, 45, 227-259. [CrossRef]

15. Pandey, M.P.; Kim, C.S. Lignin Depolymerization and Conversion: A Review of Thermochemical Methods. Chem. Eng. Technol. 2011, 34, 29-41. [CrossRef]

16. Priefert, H.; Rabenhorst, J.; Steinbüchel, A. Biotechnological production of vanillin. Appl. Microbiol. Biotechnol. 2001, 56, 296-314. [CrossRef] [PubMed]

17. Gallage, N.J.; Møller, B.L. Vanillin-bioconversion and bioengineering of the most popular plant flavor and its de novo biosynthesis in the vanilla orchid. Mol. Plant 2015, 8, 40-57. [CrossRef]

18. Martău, G.A.; Călinoiu, L.F.; Vodnar, D.C. Bio-vanillin: Towards a sustainable industrial production. Trends Food Sci. Technol. 2021, 109, 579-592. [CrossRef]

19. Banerjee, G.; Chattopadhyay, P. Vanillin biotechnology: The perspectives and future. J. Sci. Food Agric. 2019, 99, 499-506. [CrossRef]

20. Thiele, U.K. The Current Status of Catalysis and Catalyst Development for the Industrial Process of Poly (ethylene terephthalate) Polycondensation. Int. J. Polym. Mater. Polym. Biomater. 2001, 50, 387-394. [CrossRef]

21. Banella, M.B.; Bonucci, J.; Vannini, M.; Marchese, P.; Lorenzetti, C.; Celli, A. Insights into the Synthesis of Poly(ethylene 2,5Furandicarboxylate) from 2,5-Furandicarboxylic Acid: Steps toward Environmental and Food Safety Excellence in Packaging Applications. Ind. Eng. Chem. Res. 2019, 58, 8955-8962. [CrossRef]

22. Terzopoulou, Z.; Karakatsianopoulou, E.; Kasmi, N.; Tsanaktsis, V.; Nikolaidis, N.; Kostoglou, M.; Papageorgiou, G.Z.; Lambropoulou, D.A.; Bikiaris, D.N. Effect of catalyst type on molecular weight increase and coloration of poly(ethylene furanoate) biobased polyester during melt polycondensation. Polym. Chem. 2017, 8, 6895-6908. [CrossRef]

23. Papadopoulos, L.; Zamboulis, A.; Kasmi, N.; Wahbi, M.; Nannou, C.; Lambropoulou, D.A.; Kostoglou, M.; Papageorgiou, G.Z.; Bikiaris, D.N. Investigation of the catalytic activity and reaction kinetic modeling of two antimony catalysts in the synthesis of poly(ethylene furanoate). Green Chem. 2021, 23, 2507-2524. [CrossRef]

24. Ahmadnian, F.; Velasquez, F.; Reichert, K.H. Screening of different titanium(IV) catalysts in the synthesis of poly(ethylene terephthalate). Macromol. React. Eng. 2008, 2, 513-521. [CrossRef]

25. MacDonald, W.A. New advances in poly(ethylene terephthalate) polymerization and degradation. Polym. Int. 2002, 51, 923-930. [CrossRef]

26. Shigemoto, I.; Kawakami, T.; Taiko, H.; Okumura, M. A quantum chemical study on the polycondensation reaction of polyesters: The mechanism of catalysis in the polycondensation reaction. Polymer 2011, 52, 3443-3450. [CrossRef]

27. Gruter, G.-J.; Sipos, L.; Adrianus Dam, M. Accelerating Research into Bio-Based FDCA-Polyesters by Using Small Scale Parallel Film Reactors. Comb. Chem. High Throughput Screen. 2011, 15, 180-188. [CrossRef]

28. Filella, M.; Hennebert, P.; Okkenhaug, G.; Turner, A. Occurrence and fate of antimony in plastics. J. Hazard. Mater. 2020, 390, 121764. [CrossRef]

29. Terzopoulou, Z.; Karakatsianopoulou, E.; Kasmi, N.; Majdoub, M.; Papageorgiou, G.Z.; Bikiaris, D.N. Effect of catalyst type on recyclability and decomposition mechanism of poly(ethylene furanoate) biobased polyester. J. Anal. Appl. Pyrolysis 2017, 126, 357-370. [CrossRef]

30. Sánchez-Martínez, M.; Pérez-Corona, T.; Cámara, C.; Madrid, Y. Migration of antimony from PET containers into regulated EU food simulants. Food Chem. 2013, 141, 816-822. [CrossRef]

31. Payán, L.; Poyatos, M.T.; Muñoz, L.; La Rubia, M.D.; Pacheco, R.; Ramos, N. Study of the influence of storage conditions on the quality and migration levels of antimony in polyethylene terephthalate-bottled water. Food Sci. Technol. Int. 2017, 23, 318-327. [CrossRef]

32. Mialon, L.; Vanderhenst, R.; Pemba, A.G.; Miller, S.A. Polyalkylenehydroxybenzoates (PAHBs): Biorenewable aromatic/aliphatic polyesters from lignin. Macromol. Rapid Commun. 2011, 32, 1386-1392. [CrossRef]

33. Gioia, C.; Banella, M.B.; Marchese, P.; Vannini, M.; Colonna, M.; Celli, A. Advances in the synthesis of bio-based aromatic polyesters: Novel copolymers derived from vanillic acid and $\epsilon$-caprolactone. Polym. Chem. 2016, 7, 5396-5406. [CrossRef]

34. Zamboulis, A.; Papadopoulos, L.; Terzopoulou, Z.; Bikiaris, D.N.; Patsiaoura, D.; Chrissafis, K.; Gazzano, M.; Lotti, N.; Papageorgiou, G.Z. Synthesis, Thermal Properties and Decomposition Mechanism of Poly (Ethylene Vanillate) Polyester. Polymers 2019, 11, 1672. [CrossRef]

35. Karayannidis, G.P.; Roupakias, C.P.; Bikiaris, D.N.; Achilias, D.S. Study of various catalysts in the synthesis of poly(propylene terephthalate) and mathematical modeling of the esterification reaction. Polymer 2003, 44, 931-942. [CrossRef]

36. Belkov, M.V.; Brinkevich, S.D.; Samovich, S.N.; Skornyakov, I.V.; Tolstorozhev, G.B.; Shadyro, O.I. Infrared spectra and structure of molecular complexes of aromatic acids. J. Appl. Spectrosc. 2012, 78, 794-801. [CrossRef]

37. Finelli, L.; Lorenzetti, C.; Messori, M.; Sisti, L.; Vannini, M. Comparison between titanium tetrabutoxide and a new commercial titanium dioxide based catalyst used for the synthesis of poly(ethylene terephthalate). J. Appl. Polym. Sci. 2004, 92, 1887-1892. [CrossRef] 
38. Wang, S.Q.; Cheng, S.; Lin, P.; Li, X. A phenomenological molecular model for yielding and brittle-ductile transition of polymer glasses. J. Chem. Phys. 2014, 141, 094905. [CrossRef]

39. Aharoni, S.M. The cause of the grey discoloration of PET prepared by the use of antimony-catalysts. Polym. Eng. Sci. 1998, 38, 1039-1047. [CrossRef]

40. Kostoglou, M.; Bikiaris, D. Kinetic Analysis of Nanocomposites Prepared in situ Consisting of an Aliphatic Biodegradable Polyester and Fumed Silica Nanoparticles. Macromol. React. Eng. 2011, 5, 178-189. [CrossRef]

41. Bikiaris, D.N.; Achilias, D.S. Synthesis of poly(alkylene succinate) biodegradable polyesters I. Mathematical modelling of the esterification reaction. Polymer 2006, 47, 4851-4860. [CrossRef]

42. Xanthopoulou, E.; Terzopoulou, Z.; Zamboulis, A.; Papadopoulos, L.; Tsongas, K.; Tzetzis, D.; Papageorgiou, G.Z.; Bikiaris, D.N. Poly(propylene vanillate): A Sustainable Lignin-Based Semicrystalline Engineering Polyester. ACS Sustain. Chem. Eng. 2021, 9 , 1383-1397. [CrossRef]

43. Kasmi, N.; Papageorgiou, G.Z.; Achilias, D.S.; Bikiaris, D.N. Solid-State polymerization of poly(Ethylene Furanoate) biobased Polyester, II: An efficient and facile method to synthesize high molecular weight polyester appropriate for food packaging applications. Polymers 2018, 10, 471. [CrossRef] [PubMed]

44. Savvidis, G.; Karanikas, V.; Zarkogianni, M.; Eleftheriadis, I.; Nikolaidis, N.; Tsatsaroni, E. Screen-Printing of Cotton with Natural Pigments: Evaluation of Color and Fastness Properties of the Prints. J. Nat. Fibers 2017, 14, 326-334. [CrossRef] 